\title{
TINGKAT EROSI DAN RANCANGAN TEKNIK KONSERVASI TANAH DAN AIR DI SUB DAS WAEWOKI, DAS AESESA KABUPATEN NGADA PROVINSI NUSA TENGGARA TIMUR (Erosion Level and Soil and Water Conservation Engineering Plan in Waewoki Sub Watershed, Aesesa Watershed, Ngada Regency, East Nusa Tenggara Province)
}

\author{
Margareta Edo Dhoke*, Ambar Kusumandari, dan Senawi \\ Program Studi Pascasarjana Ilmu Kehutanan, Universitas Gadjah Mada, \\ Bulaksumur, Yogyakarta 55281.
}

*Penulis korespondensi. Tel: 082138444828. Email: agretdhoke@ gmail.com.

\author{
Diterima: 16 Maret 2017
}

Disetujui: 5 September 2017

\begin{abstract}
Abstrak
Kajian tingkat erosi dan rancangan Konservasi Tanah-Air (KTA) telah dilakukan di Sub DAS Waewoki DAS Aesesa Kabupaten Ngada Provinsi Nusa Tenggara Timur. Penelitian ini bertujuan untuk memprediksi tingkat erosi di Sub DAS Waewoki dan menentukan teknik KTA di Sub DAS Waewoki. Untuk memprediksi erosi, diterapkan model SWAT, dengan tahapan deliniasi DAS, pembentukan peta unit lahan, input data iklim serta data pendukung yang dibutuhkan, dan running SWAT. Dari 51 unit lahan di wilayah kajian diambil sampel tanah pada 13 titik lokasi berdasarkan GPS. Untuk merancang teknik KTA digunakan analisis klaster. Hasil penelitian menunjukkan bahwa tingkat erosi yang terjadi pada enam tahun terakhir sangat bervariasi, dari tingkat erosi sangat ringan sebesar $0,11 \%$, kelas ringan sebesar $1,38 \%$ dan kelas sedang sebesar $1 \%$. Berdasarkan model regresi ditunjukkan bahwa faktor erosi yang paling berpengaruh di lokasi penelitian adalah kelerengan, yang signifikan terhadap kriteria probabilitas yaitu 0.05. Rancangan teknik KTA dirancang pada jarak tandan terkecil dengan jumlah kelompok klaster sebayak 5 yang memiliki klasifikasi unit lahan yang berbeda-beda. Pengklasteran unit lahan menunjukkan bahwa faktor kelerengan, penggunaan lahan dan jenis tanah merupakan faktor yang paling dominan untuk terbentuknya kelompok klaster I dan V, sedangkan untuk kelompok klaster II, III, dan IV faktor yang paling dominan adalah penggunaan lahan dan jenis tanah. Model KTA yang diterapkan pada setiap kelompok klaster adalah model vegetatif dan mekanik sesuai dengan klasifikasi yang terbentuk.
\end{abstract}

Kata kunci: konservasi lahan, konservasi air, daerah aliran sungai, erosi.

\section{Abstract}

The study erosion level and Soil-Water Conservation (SWC) engineering plan was conducted in Waewoki Sub watershed, Aesesa Watershed, Ngada Regency, East Nusa Tenggara Province. This study was aimed at predicting the erosion level in Waewoki Sub watershed and determining Soil and Water Conservation engineering in Waewoki Sub watershed. To predict erosion, SWAT model was applied, with model analysis phases including watershed delineation, land unit map creation, climate data input and supporting data needed, and running SWAT. From the 51 units of land in the study area, the soil samples were collected at 13 locations using GPS. Cluster analysis was used to plan SWC engineering. The results showed that the erosion level occurred in the last six years varied widely, ranging from very mild erosion level of $0.11 \%$, mild level of $1.38 \%$, and medium level of $1 \%$. The statistical test with regression model approach showed that the most influential factor of erosion in the study site was slope, which was significant to the probability criterion, i.e. 0.05. SWC engineering plan was planned in the smallest cluster distance by 5 cluster groups with different land unit classification. Land unit clustering showed that the factors of slope, land use and soil type were the most dominant factors for the formation of the cluster groups I and $V$, while the most dominant factors for cluster groups II, III, and IV were land use and soil type. The SWC models applied to each cluster group were vegetative and mechanical models, in accordance with the classification formed.

Keywords: soil conservation, water conservation, watershed, erosion.

\section{PENDAHULUAN}

Kerusakan lingkungan di Indonesia telah menjadi keprihatinan semua pihak seperti masyarakat, pemerintah, lembaga sosial masyarakat (Nasional dan Internasional), dan lembaga pendidikan (dasar, menengah, dan tinggi). Kerusakan itu disebabkan oleh kebutuhan manusia akan lahan semakin meningkat seiring dengan bertambahnya jumlah penduduk, sehingga dapat mempengaruhi perubahan penggunaan lahan. Dalam perubahan penggunaan lahan, seringkali manusia cederung merusak lingkungan tanpa memperhatikan keseimbangan dan kelestarian alam. Akibat lanjut yang dirasakan sekarang adalah banjir, kekeringan, longsor, dan bencana alam 
lainnya. Terjadinya fenomena perubahan tata air sebagai bentuk respon alam atas interaksi manusia dan lingkungan. Suatu kesalahan dalam pengelolaan sumberdaya alam sungguh merusak siklus air. Air hujan yang jatuh di atas bumi atau tanah cepat menjadi aliran permukaan dan langsung ke sungai, sangat sedikit air yang meresap ke dalam tanah sehingga menyebabkan terjadinya erosi.

Seperti dilaporkan oleh Sudaryono (2020) beberapa permasalahan yang sering dijumpai di kawasan hutan dan Daerah Aliran Sungai (DAS) adalah peningkatan kebutuhan masyarakat, ketergantungan masyarakat yang tinggal di sekitar hutan terhadap kawasan hutan, penebangan yang berlebihan, konversi kawasan hutan menjadi lahan pertanian dan pemukiman, peningkatan jumlah penduduk, pengurangan debit air, hak milik atas lahan yang tidak diikutsertakan dengan tindakan konservasi, dan kegiatan penambangan secara berlebihan tanpa memperhatikan dampak kerusakan lingkunan. Hal tersebut juga merupakan gambaran permasalahan yang terjadi di wilayah Sub DAS Waewoki seiring dengan kemajuan teknologi dan perkembangan zaman. Dampaknya adalah dapat membawa perubahan terhadap sumberdaya alam dan lingkungan. Sebagai salah satu contoh pemanfaatan sumberdaya alam secara berlebihan di wilayah Sub DAS Waewoki adalah areal pertambangan. Areal pertambangan adalah bagian dari ekosistem yang termasuk di dalam areal penggunaan lain (APL) yang berada di luar kawasan hutan. Pemanfaatan sumberdaya alam secara berlebihan tanpa memperhatikan tindakan konservasi yang tepat, dapat mempengaruhi kelestarian sumberdaya alam dan lingkungan.

Kerusakan pada wilayah DAS yang tidak diikutsertakan dengan pengelolaan yang tepat akan berlangsung secara terus-menerus. Salah satu kerusakan yang dapat mempengaruhi kerusakan pada wilayah hilir adalah tingginya sedimentasi akibat besarnya erosi yang terjadi. Arsyad (2010) menyatakan bahwa erosi adalah pristiwa pindahnya atau terangkutnya tanah atau bagian-bagian tanah dari suatu tempat ke tempat lain oleh media alami, yaitu air dan angin. Kartasapoetra dan Sutedjo (2010) menyatakan bahwa kerugian ekonomi yang ditimbulkan akibat erosi tanah dapat dibagi atas kerugian ekonomi yang diakibatkan oleh dampak langsung di tempat kejadian erosi (on-site) maupun dampak di luar tempat kejadian erosi (off-site). Dampak langsung yang ditimbulkan dapat berupa penurunan produktivitas tanaman yang diakibatkan oleh penurunan produktivitas tanah, kehilangan unsur hara tanah dan kehilangan lapisan tanah, sedangkan dampak tidak langsung dapat berupa sedimentasi sehingga menyebabkan pendangkalan, kerusakan ekosistem perairan, memburuknya kualitas air, peningkatan frekuensi dan masa kekeringan, serta tertimbunnya lahan-lahan pertanian.

Pengelolaan DAS secara terintegrasi dapat dibantu dengan penggunaan teknologi yang berkembang saat ini seperti teknik penginderaanjauh dan sistem informasi geografis (Halengkara, 2012). Pendekatan lain adalah dengan teknik Konservasi Tanah dan Air (KTA) yakni perpaduan ilmu pengetahuan yang mengembangkan teknologi pengawetan sumberdaya alam khususnya sumberdaya tanah dan air sebagai faktor penentu kualitas lingkungan hidup (Triwanto, 2012). Dengan adanya usaha KTA, maka diharapkan dari berbagai penelitian dapat diperoleh cara-cara yang tepat untuk mengatasi problem-problem yang dihadapi masa kini maupun masa mendatang, agar kelestarian tanah dan air dapat terjaga dan berfungsi sebagaimana mestinya. Dengan demikian konservasi tanah tidaklah berarti penundaan penggunaan tanah atau pelarangan penggunaan tanah, tetapi menyesuaikan macam penggunaannya dengan kemampuan tanah dan memberikan perlakuan sesuai dengan syarat-syarat yang diperlukan, agar tanah dapat berfungsi secara lestari (Harahap, 2013). Untuk itu KTA harus mampu menata berbagai faktor seperti faktor alami penyebab erosi, faktor praktek pertanian yang tepat agar menguntungkan bagi sosial ekonomi masyarakat sehingga pemanfaatan lahan dalam upaya memperoleh manfaat dari padanya, tanah tetap terpelihara daya dukungnya dengan sangat baik.

Seiring dengan berkembangnya zaman dan peningkatan teknologi, maka pemanfaatan terhadap lahan akan semakin bertambah. Menurut Worosuprojo (2005) Pentingnya kegiatan evaluasi lahan adalah untuk menunjang dan menentukan kebijakan pengelolaan suatu kawasan. Pengelolaan DAS sebagai bagian dari pembangunan wilayah saat ini masih menghadapi berbagai masalah yang kompleks dan saling terkait. Permasalahan tersebut tidak hanya bersumber dari faktor biofisik seperti erosi, banjir dan kekeringan, namun juga terkait dengan aspek sosial ekonomi dan kelembagaan seperti belum berjalannya upaya-upaya pembangunan secara terpadu antar sektor dan antar instansi. Selain itu, tingkat kesadaran masyarakat tentang manfaat pelestarian sumberdaya alam juga sangat berpengaruh, sehingga akumulasi permasalahan di atas akan mempengaruhi keberlanjutan suatu DAS. Salah satu kawasan DAS yang perlu untuk dikaji dengan pendekatan KTA ini adalah di Sub DAS Waewoki, DAS Aesesa Kabupaten Ngada, Provinsi Nusa Tenggara Timur. Kawasan ini berperan penting dalam program pertanian di Kabuaten Ngada (Nangameka, 2012). 
Berbagai bentuk permasalah yang telah dikemukakan termasuk di Sub DAS Waewoki, DAS Aesesa ini, agar menjadi perhatian agar pengelola lebih siaga dalam menghadapi permasalahan yang timbul pada wilayah DAS baik yang berada di bagian hulu, tengah, dan hilir. Berangkat dari masalah-masalah yang terjadi pada wilayah DAS, maka peneliti akan melakukan pengkajian berupa tingkat erosi dan menentukan rancangan teknik konservasi tanah dan air di Sub DAS Waewoki.

\section{METODE PENELITIAN}

\section{Lokasi Penelitian}

Penelitian ini dilaksanakan di wilayah Sub DAS Waewoki, DAS Aesesa Kabupaten Ngada Provinsi Nusa Tenggara Timur. Luas wilayah penelitian adalah 18.137,49 Ha.

\section{Bahan dan Alat}

Alat dan bahan penelitian yang digunakan dalam penelitian antara lain adalah peta kawasan, komputer, software ArcMap 10.1, SPSS 16.0, Arc SWAT 2012, SWAT-CUP, Microsoft Office Word 2010, dan Microsoft Office Excel 2010, Global Possitioning System (GPS), soil ring sampler, roll meter, cangkul, palu atau martil, linggis, kamera, kantong plastik, kertas label, dan buku manset untuk melihat warna tanah serta alat-alat untuk survei di lapangan.

\section{Prosedur}

Data yang dikumpulkan dalam penelitian ini meliputi data primer dan data sekunder. Data primer diperoleh melalui hasil pengamatan, identifikasi, penggalian informasi secara langsung di lapangan dan wawancara. Data primer berupa pengujian sampel tanah dari lokasi. Sedangkan untuk mendapatkan data sekunder dikumpulkan dari instansi terkait yang dibutuhkan dalam penelitian ini dan melakukan studi pustaka. Data sekunder yang digunakan diantaranya adalah Peta Rupa Bumi Indonesia skala 1:25.000, Peta Administratif (Peta DAS Aesesa, Peta Sub DAS Waewoki, Peta penggunaan lahan, Peta jenis tanah, Peta kelerengan) dengan skala 1:200.000, Data curah hujan yang diperoleh dari BMKG Provinsi NTT.

\section{Penentuan Titik Sampel dan Pengambilan}

Pengambilan titik sampel penelitian dilaksanakan pada lokasi penelitian yaitu di Sub DAS Waewoki. Penentuan titik sampel menggunakan Global Possitioning System (GPS) dan sampel yang diambil pada lokasi penelitian adalah tanah. Selain penentuan titik lokasi sampel penelitian, juga dilakukan observasi terhadap kawasan Sub DAS Waewoki agar mempermudah dalam menjalankan proses penelitian serta dapat memperbaharui data sesuai dengan kondisi lapangan.

Pengambilan sampel berupa tanah diambil pada 13 titik lokasi yang berada di dalam wilayah Sub DAS Waewoki yang telah di observasi dan ditentukan terlebih dahulu dengan menggunakan Global Possitioning System (GPS), dengan memperhitungkan tenaga, biaya, dan waktu penelitian. Bentuk lokasi sampel berupa lubang dengan kedalaman \pm 2 meter dan lebar 1 meter. Terdapat 13 lubang penelitian dan setiap lubang dilakukan observasi berupa pengambilan pada setiap lapisan atau horizon tanah dengan menggunakan soil ring sample sebagai contoh tanah utuh atau tidak terganggu dan menggunakan plastik sampel sebagai contoh tanah terganggu.

\section{Observasi Kondisi Biofisik}

Observasi kondisi biofisik dilakukan untuk mengetahui kondisi penggunaan lahan. Variabel yang digunakan dalam observasi ini meliputi iklim, topografi, dan tanah. Parameter iklim yang diukur meliputi suhu dan curah hujan. Sedangkan parameter topografi dilihat berdasarkan pada peta kelerengan. Adapun, karakteristik tanah yang diamati meliputi jenis tanah, penampang profil tanah (jumlah lapisan, kedalaman maksimum akar tanaman, ketebalan lapisan, dan kandungan batuan atau pasir yang terdapat pada permukaan tanah).

\section{Pengujian Sampel Tanah}

Pengujian sampel tanah di lakukan pada Laboratorium Fakultas Pertanian Universitas Gadjah Mada. Pengujian sampel tanah bertujuan untuk mengetahui karakteristik tanah serta menjadi input yang dibutuhkan dalam menjalankan model. Parameter yang digunakan dalam setiap pengujian ini sama, namun yang membedakannya adalah penggunaan lahan untuk setiap lokasi titik sampel penelitian.

\section{Analisis Data}

Data dianalisis meliputi Analisis prediksi erosi menggunakan model SWAT (Soil and Water Assessment Tool). Selanjutnya adalah Analisis faktor yang memengaruhi erosi dilakukan dengan menggunakan pendekatan model regresi linier sederhana. Tahap terakhir adalah analisis penentuan rancangan kta untuk rehabilitasi.

Analisis prediksi erosi menggunakan model SWAT terdiri dari 4 tahap dalam menjalankan yaitu (1) delineasi DAS dilakukan menggunakan peta DEM, (2) pembentukan Peta Hydrologic Response Unit (HRU), (3) input data iklim berupa curah 
hujan dan data iklim lainnya, dan (4) running SWAT.

Analisis faktor yang memengaruhi erosi dilakukan dengan menggunakan pendekatan model regresi linier sederhana, yang mengikuti formula matematis sebagai berikut:

$\mathbf{Y}=\mathbf{a}+\mathbf{b X}$

Keterangan:

$\mathrm{Y} \quad=$ Erosi (dependen variabel)

$\mathrm{A}, \mathrm{b}=$ Konstanta

$\mathrm{X} \quad=$ Faktor yang memengaruh erosi

(independen variabel)

Hasil analisis regresi tersebut kemudian akan menghasilkan nilai koefisien korelasi (r) dan koefisien determinasi $\left(\mathrm{R}^{2}\right)$. Sugiyono (2013) menjelaskan bahwa analisis korelasi (r) dan koefisien determinasi $\left(\mathrm{R}^{2}\right)$ ini digunakan untuk mengetahui seberapa besar hubungan antara dua atau lebih variabel independen (X) terhadap variabel dependen $(\mathrm{Y})$ secara serentak. Nilai $\mathrm{r}$ berkisar antara 0 sampai 1 , nilai semakin mendekati 1 berarti hubungan yang terjadi semakin kuat, sebaliknya nilai semakin mendekati 0 maka hubungan yang terjadi semakin lemah. Detail interpretasi hasil koefisien korelasi (r) dan koefisien determinasi $\left(\mathrm{R}^{2}\right)$ disajikan pada Tabel 1.

Rancangan KTA untuk rehabilitasi lahan dirancang sebagai bagian dari proses analisis untuk menjawab tujuan yang kedua. Analisis penentuan rancangan teknik KTA dianalisis melalui pengklasteran unit lahan dengan menggunakan program SPSS. Pengklasteran unit lahan berdasarkan pada peta unit lahan yang merupakan hasil overlay (tumpang susun) peta lereng, penggunaan lahan, dan tanah di wilayah Sub DAS Waewoki.

Tabel 1. Interprestasi Nilai Koefisien Korelasi dan Koefisien Determinasi

\begin{tabular}{cc}
\hline Interval r dan $\mathbf{R}^{2}$ & Tingkat Hubungan \\
\hline $0,000-0,199$ & Korelasi sangat rendah \\
$0,200-0,399$ & Korelasi rendah \\
$0,400-0,599$ & Korelasi sedang \\
$0,600-0,7999$ & Korelasi kuat \\
$0,800-1,000$ & Korelasi sangat kuat \\
\hline
\end{tabular}

Sumber: Sugiyono (2013)

Tabel 2. Prediksi erosi di wilayah Sub DAS Waewoki

\begin{tabular}{cc}
\hline Tahun & Laju Erosi (ton/ha/tahun) \\
\hline 2009 & 10,68 \\
2010 & 38,65 \\
2011 & 29,99 \\
2012 & 100,39 \\
2013 & 49,69 \\
2014 & 18,98 \\
\hline
\end{tabular}

Sumber: Analisis Data, 2016.

\section{HASIL DAN PEMBAHASAN}

\section{Hasil Prediksi Erosi dengan Menggunakan Model SWAT}

Hardiyatmo (2012) berpendapat bahwa erosi dan sedimentasi menjadi penyebab utama berkurangnya produktivitas lahan pertanian dan berkurangnya kapasitas saluran atau sungai akibat pengendapan material hasil erosi. Prediksi erosi di Sub DAS Waewoki dilakukan dengan menggunakan model SWAT. Model ini digunakan untuk memprediksi pengaruh penggunaan lahan terhadap air, sedimen, dan penggunaan pupuk/pestisida untuk pertanian di DAS skala besar yang kompleks. Hasil prediksi erosi dengan model SWAT di Sub DAS Waewoki DAS Aesesa Kabupaten Ngada disajikan pada Tabel 2.

Pada Tabel 2, terlihat bahwa terjadi laju erosi yang berbeda pada 6 tahun terakhir di Sub DAS Waewoki. Hasil prediksi erosi menunjukkan bahwa mayoritas tingkat erosi yang terjadi di Sub DAS Waewoki termasuk tingkat erosi ringan yang tergolong ke dalam 4 tahun yaitu tahun 2010 sebesar 38,65 ton/ha/thn, tahun 2011 sebesar 29,99 ton/ha/thn, tahun 2013 sebesar 49,69 ton/ha/thn, dan tahun 2014 sebesar 18,98 ton/ha/thn, sedangkan tingkat erosi sangat ringan terjadi pada tahun 2009 sebesar 10,68 ton/ha/thn dan tingkat erosi sedang terjadi pada tahun 2012 sebesar 100,39 ton/ha/thn. Dari hasil prediksi erosi pada tabel 2 mengindikasikan bahwa kondisi wilayah Sub DAS Waewoki berkondisi baik, namun dapat mengalami perubahan seiring dengan perkembangan zaman, kemajuan teknologi dan meningkatnya jumlah penduduk. Berdasarkan kondisi di lapangan terdapat gambaran mengenai faktor-faktor yang secara langsung memengaruhi erosi yang menunjukkan perubahan dan pengaruh terhadap erosi.

Faktor-Faktor Yang Dapat Memengaruhi Erosi Kondisi Iklim (Curah Hujan), Penggunaan Lahan, Kelerengan, Tanah, dan Tekanan penduduk di Lokasi Kajian

Terdapat empat faktor yang mempengaruhi erosi yaitu iklim, jenis tanah, panjang lereng dan kemiringan lereng, serta penutupan lahan (Sutiyono, 2006). Hardiyatmo (2012) menjelaskan bahwa faktor curah hujan dan aliran permukaan saling berpengaruh, yang dapat menyebabkan timbulnya erosi. Besarnya curah hujan dapat memengaruhi volume air yang jatuh pada suatu areal tertentu sehingga berpengaruh pada proses run off. Berdasarkan bentuk DAS, diketahui bahwa Sub DAS - Sub DAS yang ada di wilayah DAS Aesesa sebagian besar menunjukkan bentuk seperti daun. Bentuk daerah yang membulat menyebabkan 
bagian hujan yang menjadi limpasan akan terkumpul secara cepat dan dapat mencapai outlet dalam waktu yang relatif cepat pula sehingga mengakibatkan hidrograf aliran naik dan turun dengan cepat. Bentuk DAS yang membulat akan memberikan debit puncak yang tinggi dan mengakibatkan meningkatnya volume sedimen yang terbawa aliran tersebut. Kondisi iklim (curah hujan) yang terdapat di Sub DAS Waewoki DAS Aesesa Kabupaten Ngada Provinsi Nusa Tenggara Timur, termasuk daerah yang memiliki tingkat curah hujan rendah. Hal ini ditunjukan dengan kondisi iklim yang tergolong pada iklim panas, sedang dan sejuk dengan 5 bulan basah yaitu bulan Oktober sampai Februari dan 7 bulan kering yaitu bulan Maret sampai September.

Selain faktor iklim (curah hujan) yang berpengaruh terhadap terjadinya erosi yang dapat menyebabkan pengendapan pada daerah hilir, penggunaan lahan dalam suatu kawasan DAS juga menjadi faktor penting yang perlu diperhatikan. Penggunaan lahan yang kurang tepat dapat menimbulkan degradasi pada wilayah DAS yang mengakibatkan lahan menjadi gundul, lahan menjadi kritis dan erosi ditambah lagi dengan kondisi lereng yang curam. Berdasarkan analisis SIG tahun 2013 dari citra satelit Provinsi Nusa Tenggara Timur, secara umum penggunaan lahan pada wilayah DAS Aesesa menunjukkan bahwa penutupan lahan berupa padang savana menempati areal terluas yaitu sebesar 96.835,1 ha atau $(82,34 \%)$. Savana merupakan areal dengan kenampakan non hutan alami berupa padang rumput dengan sedikit pohon. Di urutan kedua dan ketiga masing-masing ditempati oleh tipe penggunaan lahan berupa pertanian lahan kering dan hutan lahan kering sekunder dijumpai pada sebagian besar wilayah DAS Aesesa masingmasing dengan luasan $13.257,5$ ha atau $(11,27 \%)$ dan $12.724,9$ ha atau $(10,82 \%)$. Untuk lebih jelas data penggunaan lahan di wilayah Sub DAS Waewoki akan disajikan pada Gambar 1.

Kondisi topografi merupakan salah satu faktor yang berpengaruh terhadap erosi. Panjang lereng dan kecuraman lereng pada suatu kawasan menggambarkan suatu kondisi yang merupakan faktor perbandingan antara besarnya erosi yang terjadi pada suatu bidang tanah dengan kondisi panjang dan kecuraman lereng tertentu. Sub DAS Waewoki, DAS Aesesa Kabupaten Ngada pada umumnya berbukit dengan tingkat kemiringan lahan yang relatif tinggi. Kondisi topografi yang berbukit dengan tingkat kemiringan yang relatif tinggi ini merupakan daerah yang rawan terhadap bencana alam seperti longsor dan mempercepat terjadinya erosi. Pada Tabel 4 disajikan komposisi kemiringan lereng di Wilayah Sub DAS Waewoki.

Tabel 3. Data Curah Hujan $(\mathrm{CH}) 6$ tahun terakhir di wilayah Sub DAS Waewoki

\begin{tabular}{|c|c|c|c|c|c|c|}
\hline \multirow{3}{*}{ Tahun } & \multicolumn{6}{|c|}{ Stasiun hujan } \\
\hline & \multicolumn{2}{|c|}{ Bajawa } & \multicolumn{2}{|c|}{ Golewa } & \multicolumn{2}{|r|}{ Soa } \\
\hline & $\mathrm{CH}(\mathrm{mm})$ & $\begin{array}{c}\text { HH } \\
\text { (Hari Hujan) }\end{array}$ & $\begin{array}{c}\mathrm{CH} \\
(\mathrm{mm})\end{array}$ & $\begin{array}{c}\mathrm{HH} \\
\text { (Hari Hujan) }\end{array}$ & $\begin{array}{c}\mathrm{CH} \\
(\mathrm{mm})\end{array}$ & $\begin{array}{c}\text { HH } \\
\text { (Hari Hujan) }\end{array}$ \\
\hline 2009 & 587 & 110 & 405 & 94 & 376 & 79 \\
\hline 2010 & 783 & 166 & 733 & 223 & 433 & 149 \\
\hline 2011 & 249 & 119 & 412 & 187 & 131 & 56 \\
\hline 2012 & 290 & 106 & 327 & 149 & 230 & 115 \\
\hline 2013 & 484 & 138 & 189 & 51 & 222 & 90 \\
\hline 2014 & 411 & 96 & 116 & 38 & 140 & 38 \\
\hline
\end{tabular}

Sumber: BMKG Prov.NTT (2015)

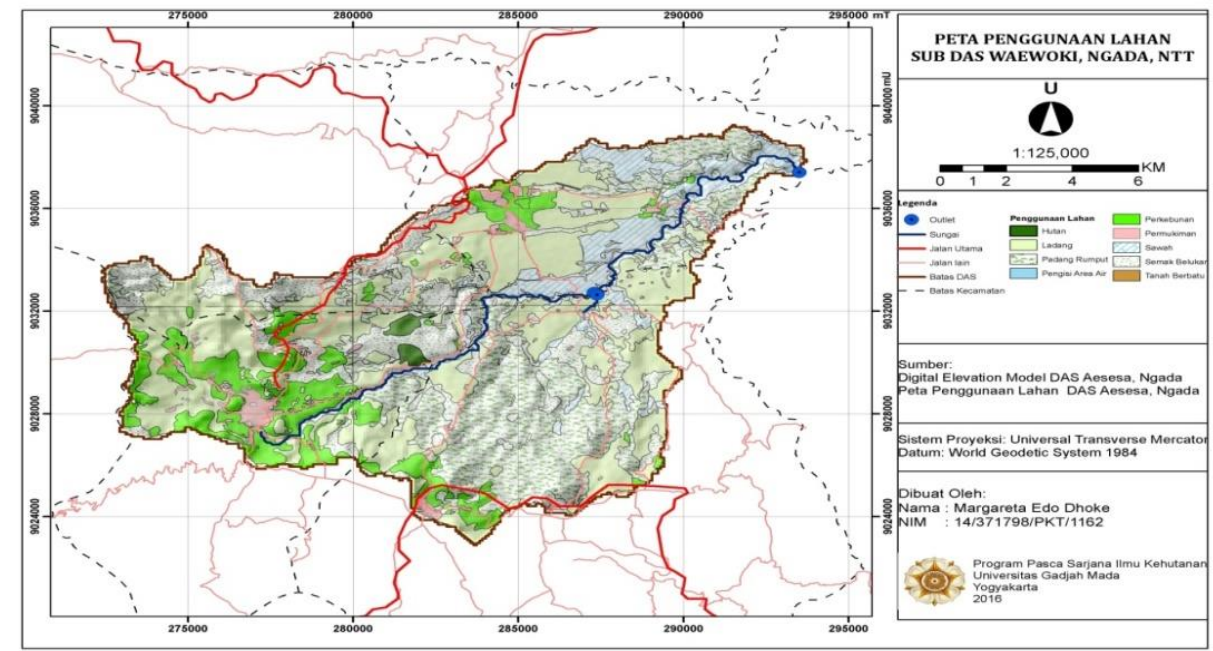

Gambar 1. Peta Penggunaan Lahan Sub DAS Waewoki 
Tabel 4. Komposisi kemiringan lereng di wilayah Sub DAS Waewoki

\begin{tabular}{ccccc}
\hline No & Kelas & Kemiringan lereng (\%) & Klasifikasi & Luas (ha) \\
\hline 1 & I & $0-8$ & Datar & $6.441,26$ \\
2 & II & $>8-15$ & Landai & 175,22 \\
3 & III & $>15-25$ & Agak Curam & $2.206,52$ \\
4 & IV & $>25-45$ & Curam & $6.325,73$ \\
5 & V & $>45$ & Sangat Curam & $2.988,76$ \\
\hline & & & & $\mathbf{1 8 . 1 3 7 , 4 9}$
\end{tabular}

Sumber: Analisis Data, 2016.

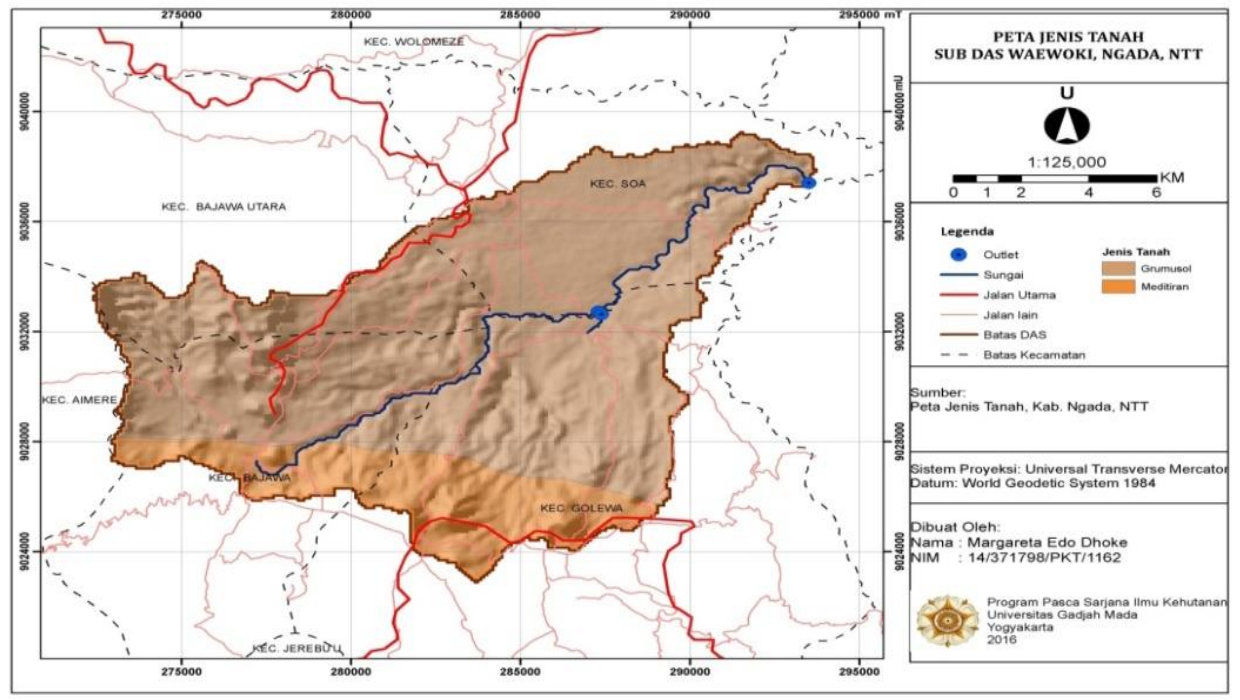

Gambar 2. Peta Penyebaran Jenis Tanah di Sub DAS Waewoki

Selain dipengaruhi oleh faktor iklim (curah hujan), tipe penutupan lahan, dan kondisi topografi pada Sub DAS Waewoki, jenis tanah yang terdapat di dalam wilayah DAS juga menjadi salah satu faktor yang berpengaruh terhadap erosi. Tanah merupakan faktor penting yang menentukan besarnya erosi yang terjadi. Jenis tanah merupakan variabel yang sangat penting dalam karakteristik suatu DAS, karena variabel ini akan sangat menentukan kemudahan proses infiltrasi dan perkolasi air hujan yang jatuh di dalam DAS tersebut. Secara garis besar jenis tanah di DAS Aesesa Kabupaten Ngada termasuk daerah vulkanis muda yang retan terhadap erosi dan jenis tanah yang tersebar di wilayah Sub DAS Waewoki adalah jenis tanah grumosol dan mediteran.

Berdasarkan hasil laboratorium tanah yang menganalisis sifat fisik (tekstur, kandungan bahan organik, permeabilitas dan tingkat kesuburan tanah) terlihat bahwa kondisi kelas tekstur tanah di kawasan Sub DAS Waewoki tergolong sebagai geluh lempungan. Dengan kondisi ini dapat menyebabkan, aliran permukaan dan erosi yang lebih intensif akibat tidak mampu mengikat air dengan baik dibandingkan dengan kondisi tanah yang padat dan tidak mudah terdispersi sehingga dapat menyebabkan infiltrasi yang besar dan memperkecil aliran permukaan dan erosi. Selain kelas tekstur tanah, kandungan bahan organik yang dihasilkan oleh kedua jenis tanah ini, rata-rata tergolong kedalam kelas sangat rendah sampai sedang. Hal ini menunjukkan dengan kandungan bahan organik yang rendah, akan memperlambat infiltrasi dan mempercepat laju aliran permukaan akibat dari tanah yang terbuka tanpa penutup tanah sebagai pelindung dari tumbukan butir hujan yang jatuh.

Kondisi permeabilitas kedua jenis tanah di Sub DAS Waewoki tergolong ke dalam kelas sangat lambat dengan rata-rata nilai permeabilitas 0,02 $\mathrm{cm} / \mathrm{jam}$. Hal ini menyebabkan air hujan yang jatuh dengan cepat menjadi aliran permukaan yang dapat meningkatkan laju erosi yang berakibat pada tingginya pengendapan. Permeabilitas berhubungan erat dengan sifat lapisan bawah tanah. Tanah yang lapisan bawahnya berupa tanah granuler, biasanya kurang peka terhadap erosi dibandingkan dengan tanah yang lapisan di bawahnya berpermeabilitas rendah. Tingkat kesuburan tanah pada suatu kawasan menjadi faktor penyebab terjadinya erosi. Kesuburan tanah yang baik akan memperbaiki pertumbuhan tanaman. Jika pertumbuhan tanaman baik, maka tanaman akan memperbaiki penutup tanah dengan menghasilkan kandungan bahan organik yang tinggi sehingga dapat menahan tubrukan butiran hujan yang jatuh dan memperkecil aliran permukaan. Gambar 2 menyajikan peta sebaran jenis tanah di wilayah Sub DAS Waewoki DAS Aesesa Kabupaten Ngada. 
Selain faktor iklim (curah hujan), penggunaan lahan, kelerengan, dan tanah, yang berpengaruh terhadap erosi tekanan jumlah penduduk juga merupakan salah satu faktor penyebab terjadinya erosi. Masalah kependudukan, baik kuantitas maupun kualitas penduduk mempunyai pengaruh penting terhadap lingkungan. Peningkatan jumlah penduduk dapat memengaruhi peningkatan pada lapangan pekerjaan, pendidikan, kesehatan, dan degradasi lingkungan. Makin besar jumlah penduduk, makin besar pula kebutuhan akan sumberdaya sehingga tekanan terhadap sumberdaya yang ada akan meningkat. Pertambahan penduduk juga berdampak pada peningkatan kebutuhan papan sehingga terjadi konversi lahan, terutama lahan pertanian menjadi lahan pemukiman. Berdasarkan pada data Badan Pusat Statistik, Kabupaten Ngada, menunjukkan bahwa pertumbuhan jumlah penduduk mengalami peningkatan dari tahun ke tahun di wilayah Sub DAS Waewoki. Untuk lebih jelas pertumbuhan jumlah penduduk di wilayah Sub DAS Waewoki, DAS Aesesa, akan disajikan pada Gambar 3.

\section{Uji Statistik dengan Pendekatan Model Regresi pada Faktor-faktor Erosi yang Paling} Berpengaruh di Lokasi Kajian

Hasil analisis SPSS menunjukkan bahwa nilai koefisien korelasi (r) sebesar 0,887. Menurut Sugiyono (2013), data tersebut menunjukkan tingkat hubungan korelasi sangat kuat antara variabel terikat dengan variabel bebas. Berdasarkan hasil output SPSS menunjukkan model summary dengan besarnya nilai adjusted $\mathrm{R}^{2}$ adalah 0,614 , hal ini berarti $61,4 \%$ tingkat erosi dapat dijelaskan oleh variasi dari ke empat variabel independen yaitu erodibilitas, lereng, penggunaan lahan dan erosivitas. Sedangkan sisanya $(100 \%-61,4 \%=$ $38,6 \%$ ) dijelaskan oleh sebab-sebab yang lain di luar model.

Dari uji anova diperoleh nilai $\mathrm{F}$ hitung sebesar 4.977 dengan probabilitas 0.111 . Mengingat nilai probabilitas jauh lebih besar dari 0,05, maka variabel bebas yaitu erodibilitas, lereng, penggunaan lahan dan erosivitas tidak secara bersama-sama berpengaruh terhadap variabel terikat yaitu erosi.

Berdasarkan hasil analisis pada Tabel 5 menunjukkan bahwa dari keempat variabel independen yang dimasukan ke dalam model regresi, variabel erosivitas, erodibilitas, dan land used tidak signifikan hal ini dapat dilihat dari probabilitas signifikan untuk erosivitas sebesar 0.12 , erodibilitas sebesar 0.16 dan land used sebesar 0.74 ketiga variabel ini jauh diatas kriteria probabilitas yaitu 0.05. Sedangkan variabel lereng signifikan dengan kriteria probabilitas yaitu 0.05 dengan nilai probabilitas variabel lereng sebesar 0.05. Dari hasil ini dapat disimpulkan bahwa variabel terikat (dependen) yaitu erosi dapat dipengaruhi oleh variabel bebas (independen) yaitu lereng.

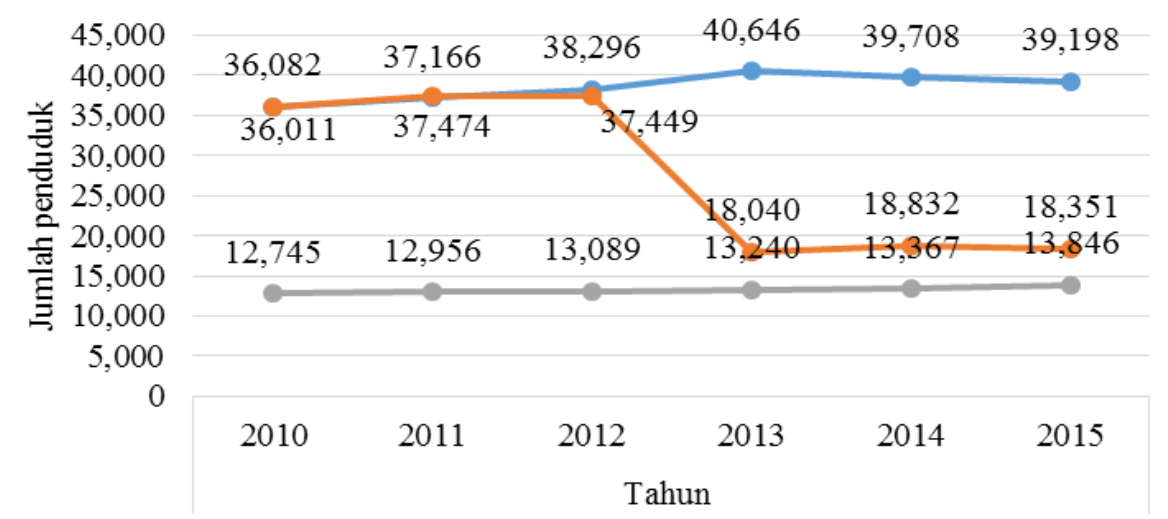

- Bajawa - Golewa

Gambar 3. Grafik pertumbuhan penduduk di wilayah Sub DAS Waewoki

Tabel 5. Uji signifikansi parameter individual (uji statistik t)

\begin{tabular}{|c|c|c|c|c|c|}
\hline \multirow[t]{2}{*}{ Model } & \multicolumn{2}{|c|}{ Unstandardized Coefficients } & $\begin{array}{l}\text { Standardized } \\
\text { Coefficients }\end{array}$ & \multirow[t]{2}{*}{$\mathrm{t}$} & \multirow[t]{2}{*}{ Sig } \\
\hline & $\mathrm{B}$ & Std. Error & Beta & & \\
\hline 1 (Constant) & 116.932 & 26.287 & & 4.448 & .02 \\
\hline lereng & -71.641 & 22.724 & -1.155 & -3.153 & .05 \\
\hline erosivitas & -.007 & .003 & -.787 & -2.147 & .12 \\
\hline erodibilitas & -996.125 & 594.430 & -.642 & -1.676 & .16 \\
\hline land used & 26.880 & 77.374 & .171 & .347 & .74 \\
\hline
\end{tabular}

Sumber: Analisis Data, 2016. 
Unit Lahan Sebagai Dasar Dalam Menentukan Rancangan Teknik KTA Untuk Rehabilitasi Lahan

Unit lahan merupakan bagian dari lahan yang mempunyai karakteristik yang spesifik. Karakteristik lahan merupakan atribut lahan yang dapat diukur atau diestimasi, misalnya kemiringan, curah hujan, tekstur tanah, dan kerapatan vegetasi. Berdasarkan aplikasi model SWAT dalam pembentukan Hydrologic Response Unit (HRU) atau pembentukan peta unit lahan yang merupakan hasil overlay dari peta penggunaan lahan, peta tanah, dan peta lereng terdapat 51 unit lahan yang terdapat di wilayah Sub DAS Waewoki. Untuk lebih jelas peta pembentukan HRU akan disajikan pada Gambar 4.
Berdasarkan pada Gambar 4 dengan memperhitungkan tenaga, biaya dan waktu penelitian, maka pengambilan sampael tanah yang merupakan salah satu variabel dalam input model prediksi erosi akan diambil pada 13 titik secara menyebar dan mewakili secara keseluruhan wilayah Sub DAS Waewoki dengan memperhatikan kondisi penggunaan laahan. Pengambilan titik sampel tanah dengan menggunakan Global Possitioning System (GPS), kemudian memilih titik-titik yang telah dilakukan pengecekan di lapangan. Untuk lebih jelas 13 titik sampel tanah di wilayah Sub DAS Waewoki, DAS Aesesa Kabupaten Ngada akan disajikan dalam Gambar 5.

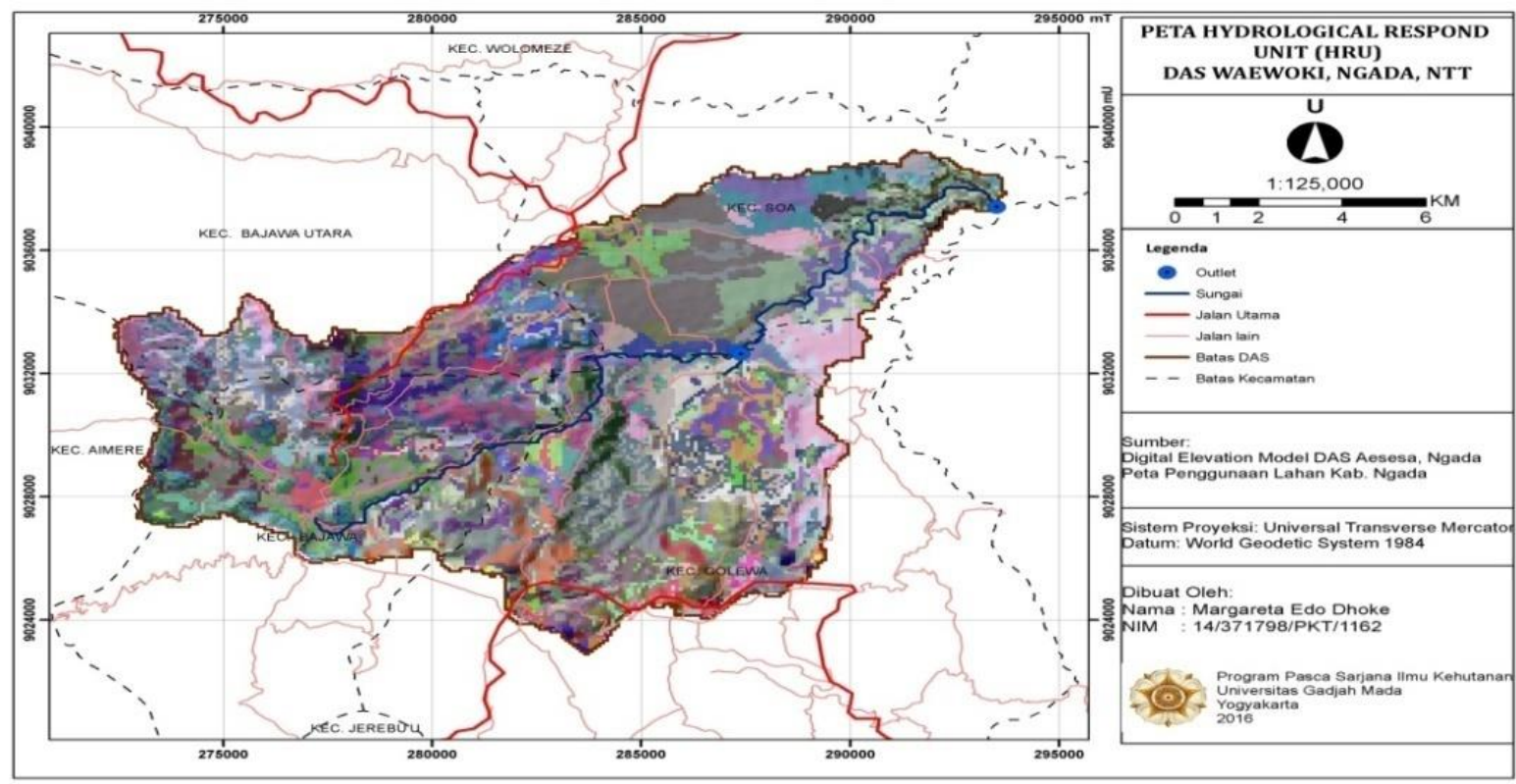

Gambar 4. Peta Hydrologic Response Unit (HRU) di Sub DAS Waewoki

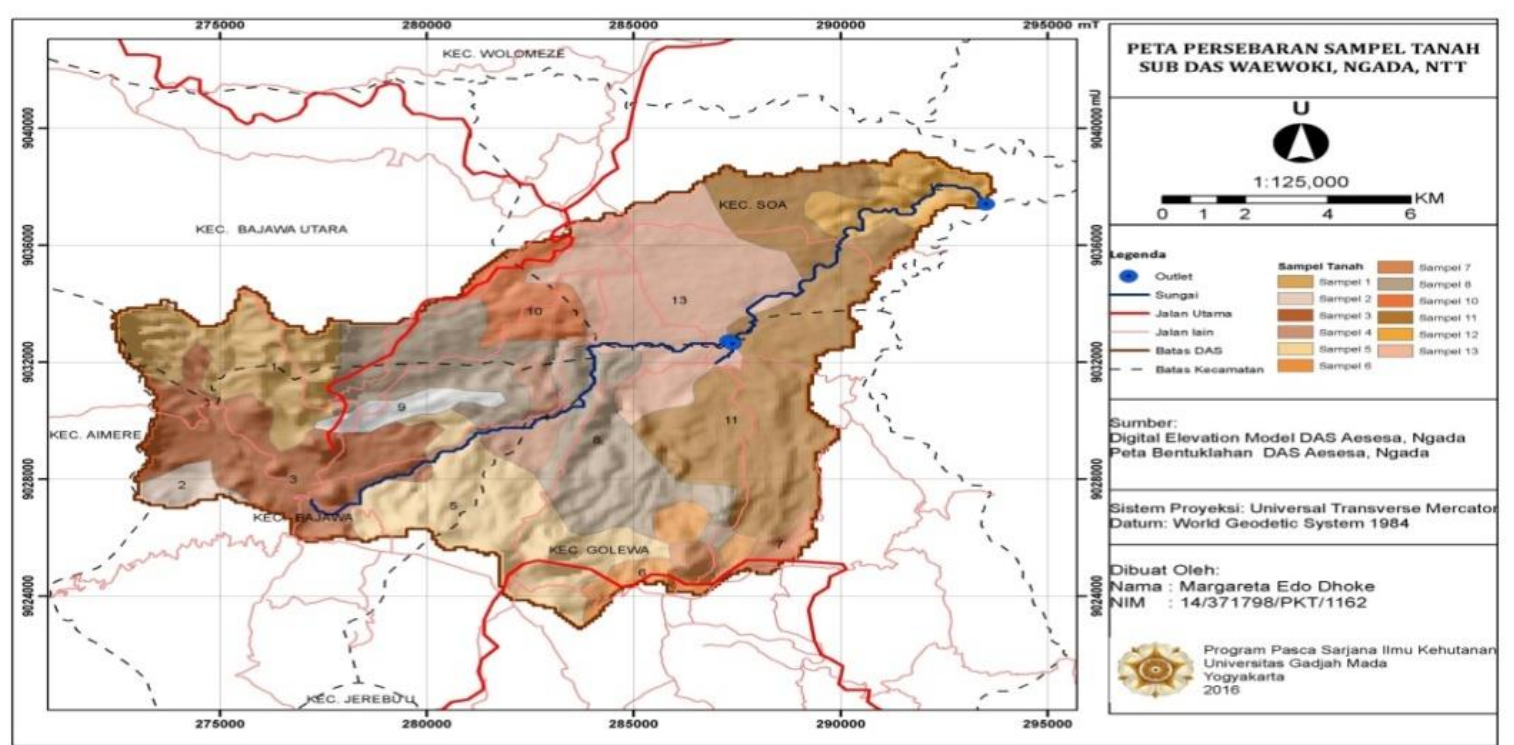

Gambar 5. Peta persebaran titik sampel tanah di Sub DAS Waewoki. 


\section{Rancangan Teknik Konservasi Tanah dan Air}

Rancangan teknik KTA dirancang pada 51 unit lahan, yang merupakan hasil overlay peta penggunaan lahan, peta lereng dan peta tanah di Sub DAS Waewoki. Rancangan teknik KTA dirancang dengan cara mengklasterkan unit lahan, agar menjadi kelompok-kelompok klaster yang lebih sederhana dan jelas. Pengklasteran ini ditujukan untuk mengelompokkan lahan berdasarkan hasil prediksi erosi dengan mempertimbangkan faktor-faktor yang berpengaruh terhadap erosi yaitu iklim (curah hujan), tanah, kelerengan, penggunaan lahan, dan tindakan manusia. Pengklasteran serupa juga ditunjukkan dengan baik untuk kawasan DAS Ngrancah Kulonprogo (Kusumandari, 2012). Hasil pengklasterkan berupa diagram dapat dilihat pada Gambar 6. Dari hasil pengklasteran akan dipilih jarak tandan terkecil untuk dirancang teknik KTA sesuai dengan klasifikasi yang terbentuk pada setiap kelompok klaster. Untuk lebih jelas hasil pengklasteran unit di wilayah Sub DAS Waewoki akan disajikan pada Gambar 6.

Berdasarkan Gambar 6, maka dipilih jarak tandan terkecil untuk dianalisis dan dirancang teknik KTA sesuai dengan klasifikasi pada setiap unit lahan yang terbentuk. Berikut ini adalah Tabel 8 yang menyajikan kelompok klaster dan klasifikasi pada setiap kelompok klaster yang ambil untuk dirancang teknik KTA pada wilayah Sub DAS Waewoki DAS Aesesa Kabupaten Ngada.

Berdasarkan sajian data pada Tabel 8 menginformasikan bahwa pada jarak tandan terendah terbentuk 5 kelompok klaster dengan klasifikasi yang berbeda pada setiap kelompok klaster, sehingga dalam merancang teknik KTA harus disesuaikan pada kondisi yang terdapat pada setiap kelompok klasternya. Gambar 7 menjelaskan rancangan teknik KTA pada setiap kelompok klaster sesuai dengan klasifikasinya.

\section{KESIMPULAN}

Sub DAS Waewoki dengan luas 18.137,49 ha secara umum menujukkan kondisi yang baik, namun akan mengalami perubahan seiring dengan berkembangnya zaman, kemajuan teknologi dan pertambahan penduduk. Hasil tingkat erosi menunjukkan bahwa laju erosi yang terjadi tergolong kedalam kelas sangat ringan sebesar 0,11 $\%$, kelas ringan sebesar 1,38 \% dan kelas sedang sebesar $1 \%$. Faktor yang paling berpengaruh terhadap erosi adalah kelerengan. Hal ini dibuktikan dengan hasil output analisis SPSS dengan pendekatan model regresi linear yang menunjukkan bahwa nilai probabilitas variabel lereng sebesar 0.05 yang dinyatakan signifikan dengan kriteria probabilitas yaitu 0.05 .

Rancangan teknik KTA dirancang berdasarkan hasil pengklasteran unit lahan. Terdapat 51 unit lahan di wilayah Sub DAS Waewoki. Pada jarak tandan terkecil dipilih untuk menentukan rancangan teknik KTA sesuai dengan klasifikasi yang terdapat pada setiap kelompok klaster. Faktor pembeda utama antar kelompok klaster adalah faktor kelerengan (Ls), penggunaan lahan (C) dan tanah. Untuk menanggulangi faktor penyebab terjadinya erosi, maka rancangan teknik KTA yang terbentuk yaitu metode vegetatif dan mekanik berdasarkan pada klasifikasi setiap kelompok klaster.

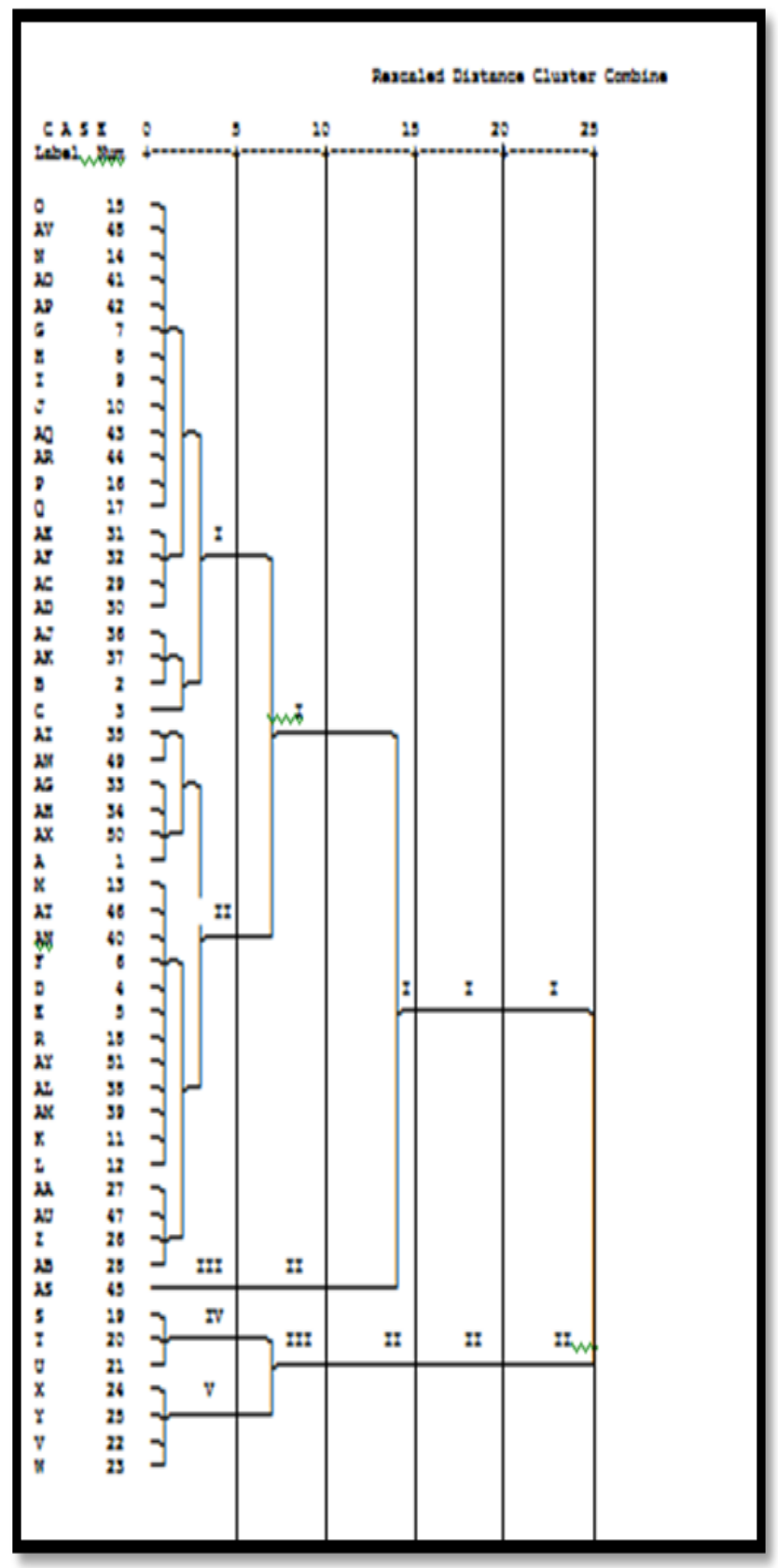

Gambar 6. Dendrogram pengklasteran unit lahan di Sub DAS Waewoki 


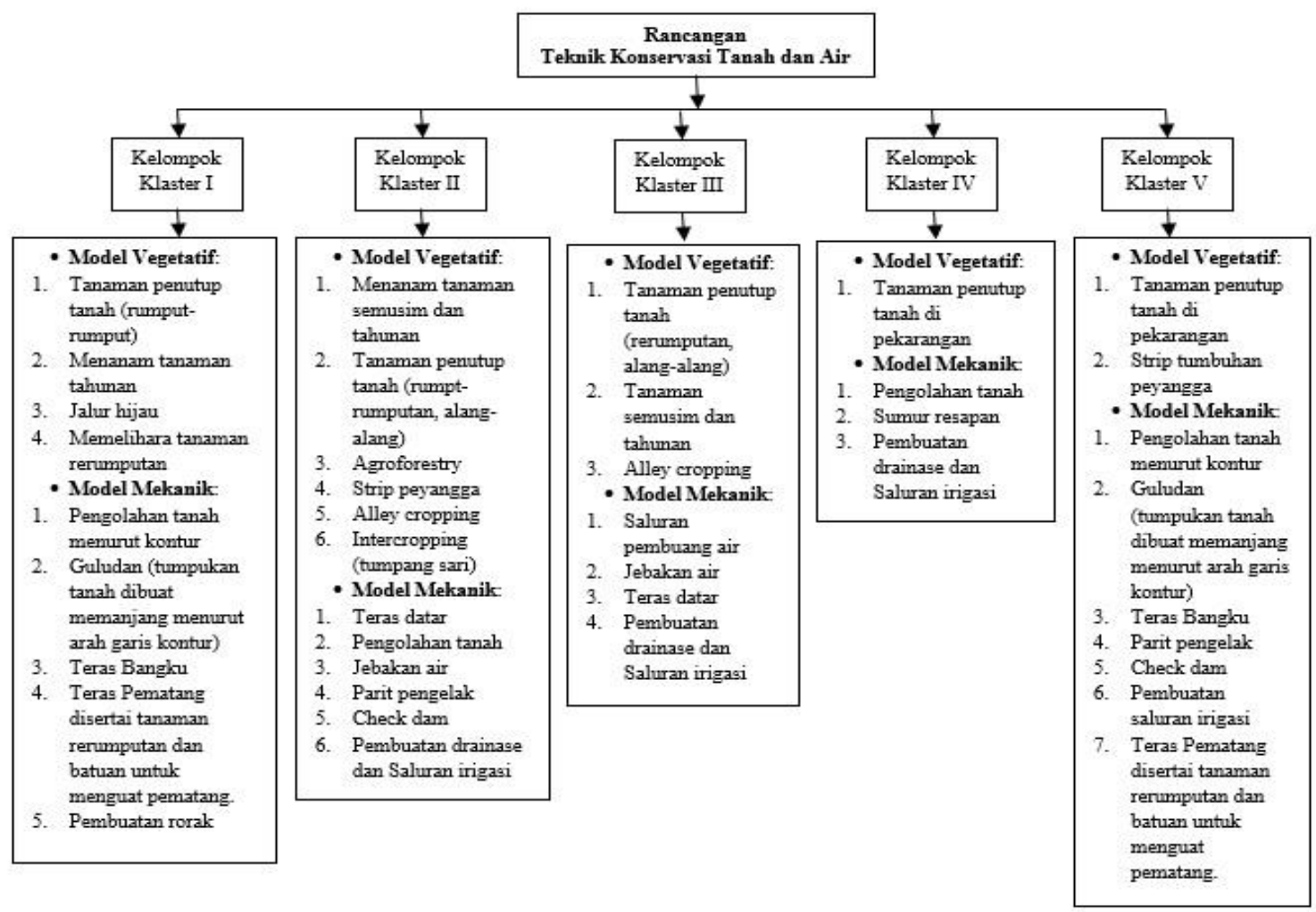

Gambar 7. Rancangan teknik KTA di Sub DAS Waewok.

Tabel 8. Klasifikasi setiap kelompok klaster dalam untuk dirancang teknik KTA.

\begin{tabular}{|c|c|c|c|}
\hline No & $\begin{array}{l}\text { Kelompok } \\
\text { Klaster }\end{array}$ & & Klasifikasi Kelompok Klaster \\
\hline \multirow{6}{*}{1.} & \multirow{6}{*}{ I } & 1. & $\begin{array}{l}\text { Penggunaan lahan berupa: padang rumput, semak belukar, ladang, } \\
\text { perkebunan, hutan, sawah tadah hujan. }\end{array}$ \\
\hline & & 2. & Penggunaan lahan paling dominan adalah padang rumput. \\
\hline & & 3. & Penggunaan lahan paling sedikit adalah hutan dan sawah tadah hujan. \\
\hline & & 4. & Jenis tanah yang paling dominan adalah tanah Grumosol. \\
\hline & & 5. & $\begin{array}{l}\text { Kelas lereng yang terdapat adalah: kelas IV (> 25-45 \%) dan kelas V (> } 45 \\
\%) \text {. }\end{array}$ \\
\hline & & 6. & $\begin{array}{l}\text { Kelas lereng yang paling dominan adalah: kelas lereng IV (> } 25-45 \%) \\
\text { dengan kategori curam. }\end{array}$ \\
\hline \multirow{6}{*}{2.} & \multirow{6}{*}{ II } & 1. & $\begin{array}{l}\text { Penggunaan lahan berupa: padang rumput, semak belukar, perkebunan, } \\
\text { sawah tadah hujan, hutan, dan sawah. }\end{array}$ \\
\hline & & 2. & $\begin{array}{l}\text { Penggunaan lahan paling dominan adalah: padang rumput dan semak } \\
\text { belukar. }\end{array}$ \\
\hline & & 3. & Penggunaan lahan paling sedikit adalah hutan dan sawah. \\
\hline & & 4. & Jenis tanah yang paling dominan adalah tanah Grumosol. \\
\hline & & 5. & $\begin{array}{l}\text { Kelas lereng yang terdapat adalah: kelas I }(0-8 \%) \text {, kelas II }(>8-15 \%) \text {, dan } \\
\text { kelas III }(>15-25 \%) \text {. }\end{array}$ \\
\hline & & 6. & $\begin{array}{l}\text { Kelas lereng yang paling dominan adalah: kelas lereng I (0-8 \%) dengan } \\
\text { kategori datar. }\end{array}$ \\
\hline \multirow{3}{*}{3.} & \multirow{3}{*}{ III } & 1. & Penggunaan lahan berupa: Tanah berbatu. \\
\hline & & 2. & Jenis tanah yang terdapat adalah tanah Grumosol. \\
\hline & & 3. & Kelas lereng yang terdapat adalah: kelas I (0-8\%) dengan kategori datar. \\
\hline \multirow{4}{*}{4.} & \multirow{4}{*}{ IV } & 1. & Penggunaan lahan berupa: pemukiman. \\
\hline & & 2. & Jenis tanah yang paling dominan adalah tanah Grumosol. \\
\hline & & 3. & Kelas lereng yang terdapat adalah: kelas I (0-8 \%) dan kelas III (> 15-25 \%). \\
\hline & & 4. & $\begin{array}{l}\text { Kelas lereng yang paling dominan adalah: kelas lereng I (0-8 \%) dengan } \\
\text { kategori datar. }\end{array}$ \\
\hline \multirow{4}{*}{5.} & \multirow{4}{*}{$\mathrm{V}$} & 1. & Penggunaan lahan berupa: pemukiman \\
\hline & & 2. & Jenis tanah yang terdapat adalah tanah Grumosol dan tanah Mediteran. \\
\hline & & 3. & $\begin{array}{l}\text { Kelas lereng yang terdapat adalah: kelas IV (> 25-45 \%) dan kelas V (> } 45 \\
\%) \text {. }\end{array}$ \\
\hline & & 4. & Kategori kelas lereng adalah curam sampai Sangat curam. \\
\hline
\end{tabular}




\section{DAFTAR PUSTAKA}

Arsyad, S., 2010. Konservasi Tanah dan Air. Cetakan ke-2, Penerbit IPB Press, Bogor.

Halengkara, L., Gunawan, T., dan Purnama, S., 2012. Analisis Kerusakan Lahan Untuk Pengelolaan Daerah Aliran Sungai Melalui Integrasi Teknik Penginderaanjauh Dan Sistem Informasi Geografis. Majalah Geografi Indonesia, 26(2):149-173.

Harahap, E.M., 2013. Konservasi Tanah dan Air Lanjutan. USU-Medan.

Hardiyatmo, H.C., 2012. Tanah Longsor dan Erosi. Cetakan Pertama. Gadjah Mada University Press, Yogyakarta.

Kartasapoetra, A.G dan Sutedjo, M.M., 2010. Teknologi Konservasi Tanah dan Air. Cetakan Ke-6, Dicetak oleh: PT Asdi Mahasatya, Jakarta.

Kusumandari, A., Marsono, D., Sabarnurdin, S., dan Gunawan, T., 2012. Pengklasteran Erosi di Sub DAS Ngrancah Kulonprogo. J. Manusia \& Lingkungan, 19(1):95-103.
Nangameka, Y., 2012. Kajian Pengelolaan Potensi Sumber Daya Air Daerah Aliran Sungai (DAS), Untuk Penentuan Proyek Pertanian Di Kabupaten Ngada, Nusa Tenggara Timur. Agribios, 10(2):1-15.

Sudaryono, 2002. Pengelolaan Daerah Aliran Sungai (DAS) Terpadu, Konsep Pembangunan Berkelanjutan. Jurnal Teknologi Lingkungan, 3(2):153-158.

Sugiyono., 2013. Metode Penelitian Kuantitatif, Kualitatif dan $R \& D$. Cetakan Ke-19, Penerbit Alfabeta, CV, Bandung.

Sutiyono, A.P., 2006. Penggunaan Model AGNPS Berbasis Sistem Informasi Geografis dalam Analisis Karateristik Hidrologi Sub DAS Ciawitali Subang Jawa Barat. Skripsi. Fakultas Kehutanan, Institut Pertanian Bogor.

Worosuprojo, S., 2005. Klasifikasi Lahan Untuk Perencanaan Penggunaan Lahan di Kabupaten Sleman Yogyakarta. Jurnal Forum Perencanaan Pembangunan, edisi khusus 2005. 